\title{
Acquisition Completion or Abandonment: The Effect of Revealed Comparative Advantage in the M\&A Pre-integration Process
}

\author{
Doan Thu Trang ${ }^{*}$ \\ VNU International School, Building G7-G8, 144 Xuan Thuy, Cau Giay, Hanoi, Vietnam
}

Received 07 April 2017

Revised 05 May 2017, Accepted 28 June 2017

\begin{abstract}
This paper explores the effect of revealed comparative advantage in the M\&A preintegration process. Revealed comparative advantage reflects the advantage of a particular industry in trade compared to other industries. It is measured by the share of a sector's exports in the overall country-wide exports, compared to the share of that sector's exports in the total exports of a group of countries. In this study, I examine whether revealed comparative advantage could determine the completion likelihood of an M\&A deal and the duration of M\&A pre-integration process. A binary logistic regression model and a multiple regression model were performed with a sample of 260 mergers and acquisitions to test for the possible relationships. The evidence demonstrates that revealed comparative advantage of targets can reduce the likelihood of consummating acquisition deals as well as prolong the decision-making period of M\&A announcements. Additionally, revealed comparative advantage of acquirers' industries can help to reduce the length of the preintegration phase.
\end{abstract}

Keywords: Acquisition completion, acquisition abandonment, acquisition duration, revealed comparative advantage.

\section{Introduction}

Research on the pre-integration process of an M\&A (mergers and acquisitions) deal has attracted increasing interests and attention from scholars in the recent years $[1,2]$. Researchers show particular interests on investigating the determinants of two indicators of firm performance in this process, namely the completion likelihood of an M\&A announcement (M\&A completion likelihood) and the duration of the pre-integration process $(M \& A$ pre-integration duration) [1, 3, 4]. Empirical findings from

\footnotetext{
${ }^{*}$ Tel.: 84-024-35575992.

Email: trangdt@isvnu.vn

https://doi.org/10.25073/2588-1116/vnupam.4085
}

previous studies demonstrate a number of factors that influence these two indicators, for example method of payment [5], cultural and institutional differences in cross-border acquisitions [2], and experience with prior M\&A deals [4]. Despite of the contributions of these studies, the research stream on the M\&A pre-integration process is still in a developmental stage, leaving significant room for further research.

With an attempt to contribute to this research stream, the objective of this paper is to explore whether the completion likelihood of an M\&A announcement and the duration of the pre-integration process depend on the revealed comparative advantage of both partners involved in the focal deal. Revealed comparative advantage 
is a popular notion in international economics, which is used to identify strong and weak firms at the industry-country level. Revealed comparative advantage is illustrated through the share of a sector's exports in the overall country-wide exports, compared to the share of that sector's exports in the total exports of a group of countries [6]. If this rate is larger than 1 , it is said that a comparative advantage is revealed for the focal sector. I suggest that revealed comparative advantage of acquirers and targets will offer firms different benefits, which facilitate firms in completing M\&A deals in a reasonable time.

This study is expected to contribute to both the literature on the M\&A pre-integration process and research on revealed comparative advantage in the context of M\&As. The study investigates a novel factor, namely revealed comparative advantage, which has hardly been studied in strategic management field. In research so far, revealed comparative advantage has been widely used in studies related to patterns of trade or in research examining the competitiveness of particular industries or countries [7-9]. With regard to the link between revealed comparative advantage and M\&As, to the best of my knowledge, existing literature only considers revealed comparative advantage as one of the incentives of M\&As [10, 11]. Hence, with this study, I hope to provide more in-depth knowledge on the relationship between revealed comparative advantage and M\&As performance.

\section{The M\&A pre-integration process}

Following prior research [2-4], I define the $M \& A$ pre-integration process as the stage between the public announcement of an intended M\&A deal and the announcement of its completion or abandonment.

As prior work has demonstrated, completing an M\&A announcement in a reasonable time frame is of great importance to both firms and managers that are involved in the deal due to many reasons. First, abandoned M\&A transactions can cause considerable financial damages to both acquirers and targets, such as the expenses to identify an appropriate target or acquirer [12], investigation costs for completion authorities [13] and payments made for financial, accounting and legal services [2]. Second, the failure in completing a transaction may negatively affect firms' reputation and credibility [14]. As a result, not only firms' business activities may be damaged, but also the likelihood of completing subsequent M\&A deals possibly decreases. Third, failing to complete an M\&A announcement may lead managers to a decrease in their reputation as leaders, which could result in lower managerial compensation and a negative impact on future career prospects [15].

Considering these significant losses, a number of papers have investigated the determinants of M\&A completion likelihood and show that it can be easier to consummate an M\&A deal if the transaction is financed by cash, when managers have an understanding regarding cultural and institutional differences between the two firms, or when acquiring firms are more experienced in striking M\&A deals [2, 4]. Yet, these papers also emphasize that the question on factors affecting the probability of completing an M\&A announcement and the duration of an M\&A integration process still needs more indepth answers.

\section{Hypotheses on the influences of revealed comparative advantage in the M\&A pre-integration process}

The concept of "revealed comparative advantage" was introduced by Liesner (1958) [16] and later operationalized, with its well-known measure, the Balassa index, in the paper: "Trade Liberalization and 'Revealed' Comparative Advantage" [6]. According to Balassa (1965) [6], revealed comparative advantage is considered in a group of industries and a group of reference countries. If we have a group of industries $I$ and a group of reference countries $J$, the Balassa index (henceforth: $\mathrm{BI}$ ) of revealed comparative advantage of sector $i \in I$ from country $j \in J$ is defined as: 


$$
B I_{i, t}^{j}=\frac{\mathrm{X}_{\mathrm{i}, \mathrm{t}}^{\mathrm{j}} / X_{t}^{j}}{\mathrm{X}_{\mathrm{i}, \mathrm{t}}^{\mathrm{J}} / X_{t}^{J}},
$$

in which

$B I_{i, t}^{j}=$ the Balassa index of revealed comparative advantage of sector $i \in I$ from country $j \in J$ in period $t \in T$

$X_{i, t}^{j}=$ value of exports of sector $i \in I$ from country $j \in J$ in period $t \in T$.

$X_{t}^{j}=$ total value of exports of country $j \in J$ in period $t \in T\left(X_{t}^{j}=\sum_{i} \mathrm{X}_{\mathrm{i}, \mathrm{t}}^{\mathrm{j}}\right)$.

$X_{i, t}^{J}=$ value of exports of sector $i \in I$ from the group of reference countries $J$ in period $t \in T\left(X_{i, t}^{J}=\sum_{j} \mathrm{X}_{\mathrm{i}, \mathrm{t}}^{\mathrm{j}}\right)$.

$X_{t}^{J}=$ total value of exports of the group of reference countries $J$ in period $t \in T$ $\left(X_{t}^{J}=\sum_{i} \sum_{j} X_{\mathrm{i}, \mathrm{t}}^{\mathrm{j}}\right)$.

If $B I_{i, t}^{j}>1$, sector $i$ of country $j$ is regarded to have a revealed comparative advantage. Firms coming from the industry that has a comparative advantage can benefit from the low marginal costs, compared to other industries, thus producing and exporting at a higher level than other firms. These firms are also considered as strong firms, compared to weak firms with $\mathrm{BI}<1$.

I expect that M\&A completion likelihood and the length of the M\&A pre-integration process would be influenced by the fact that acquirers and/or targets are active in a strong or weak industry. However, the effect of the revealed comparative advantage of acquirers' industries on acquisition completion likelihood and acquisition duration may not be the same as the effect of the revealed comparative advantage of targets' industries. Therefore, in the following paragraphs, I will firstly discuss the impact of the revealed comparative advantage of acquirers' industries then argue and formulate hypotheses on that of the revealed comparative advantage of targets' industries on M\&A completion likelihood and M\&A pre-integration duration.

\subsection{The impact of revealed comparative advantages of acquirers' industries in the $M \& A$ pre-integration process}

With the revealed comparative advantage of their industries, strong firms are able to offer targets more resources and benefits than weak firms, which can help increase the attractiveness of the offer as well as reduce the concerns of targets about the future of the integration. Targets, therefore, may be more motivated to engage in the merger or acquisition with a strong acquirer due to the advantages that they can accrue. Thus, acquisitions which include a strong acquirer may be more likely to be completed than transactions with a weaker acquirer. In addition, theoretical and empirical evidence demonstrates that strong firms appear to undertake more takeovers than weak firms $(10,11)$. Therefore, I suppose that strong firms have more opportunities to gain knowledge, skills and experience related to the M\&A process than weak firms. These skills and experience may help strong acquirers to efficiently solve various mandatory tasks in the decision-making period, such as negotiating with shareholders, dealing with the press or handling accounting and banking services, which can increase the probability of completing M\&A transactions as well as reduce the time-lapse of completing them. Furthermore, from the bids that they have undertaken, strong firms may also gain the skills and experience to deal with other firms who also want to bid for the target. Since the presence of other bidders is often considered to be one of the main obstacles in the process of acquiring a target of a firm [17], I suppose that with the advantage of having more experience in dealing with other bidders, strong firms have higher probability to successfully complete takeovers than weaker firms.

Based on the above arguments, I predict:

Hypothesis 1a: There is a positive relationship between the revealed comparative advantage of 
the acquirer's industry and the likelihood that an announced M\&A will be completed.

Hypothesis 1b: There is a negative relationship between the revealed comparative advantage of the acquirer's industry and the timelapse between the announcement of an M\&A transaction and its completion.

3.2. The impact of revealed comparative advantages of targets' industries in the $M \& A$ pre-integration process

Since every firm wants to retain their independence [17], targets may not be very willing to engage in a relationship in which they will be the junior partner. Particularly, for strong targets which can accrue the comparative advantage from their industries, the desire to defend against acquirers may be even stronger, possibly due to a belief that they would be able to survive and do better on their own [17]. In addition to this determination, strong targets also hold power created by their advantage of low marginal costs to resist an announced takeover. Since a number of past papers also suggest that the willingness of targets to partner in an M\&A transaction is crucial and necessary to its likelihood of completion [18, 19], I suppose that the stronger targets are, the more they will hesitate to consummate an announced takeover, which will possibly reduce the probability to complete the transaction, as well as prolong the period of decision-making.

Moreover, given that one of the motives of M\&As is seeking for increasing size and scale, cost reduction, and faster growth [17], firms that are active in industries which have a revealed comparative advantage appear to be very attractive and desirable targets to bidders. As a result, the higher revealed comparative advantage that targets' industries have, the number of bidders for those targets will be greater. In addition, the determination to acquire these targets may also be very strong for all bidders, since no firms want such attractive targets to be taken over by another acquirer, who may possibly become their rival later on [17]. Therefore, the more attractive targets are, the higher the level of competition between acquirers may be, which will clearly reduce the probability of completing a transaction, as well as increase the length of the pre-completion process.

Therefore, I propose:

Hypothesis 2a: There is a negative relationship between the revealed comparative advantage of the target's industry and the likelihood that an announced M\&A will be completed.

Hypothesis $2 b$ : There is a positive relationship between the revealed comparative advantage of the target's industry and the time-lapse between the announcement of an M\&A transaction and its completion.

\section{Data and methodology}

\subsection{Data}

The sample of data was derived from Zephyr, a database which contains more than 500,000 M\&As, initial public offerings, and venture capital deals, in which worldwide companies are involved. Regarding revealed comparative advantage, I used the Balassa index list ${ }^{1}$ derived by Prof. Dr. Charles van Marrewijk ${ }^{2}$. This list provides Balassa indices for all manufacturing sectors, in 21 OECD countries from 1960 to 2000. Since my main database - Zephyr - does not provide much data of transactions occurring before 1995, to ensure that I could find Balassa indices for the industries of all of the firms in my sample, I restricted my sample to M\&A transactions in manufacturing sectors, located in the 21 countries in the Balassa index list (which is also my "group of reference countries") during 1995 and 2000.

After a screening procedure and steps of eliminating observations with missing data, I

\footnotetext{
${ }^{1}$ This list is available upon request.

2 Prof. Dr. Charles van Marrewijk is a Professor of Economics at Utrecht University (The Netherlands). For more information please visit his home page at www.charlesvanmarrewijk.nl.
} 
had a sample of data with 260 mergers and acquisitions, which are in twelve different manufacturing sectors ${ }^{3}$ and occurred between 1995 and 2000. $91.57 \%$ of the sample are completed transactions. The mean time to complete these transactions is approximately 112 days.

\subsection{Variables}

\subsubsection{Dependent variables}

My first dependent variable, $M \& A$ completion likelihood, is a dummy variable, which takes the value of 1 if the focal transaction is "completed" and 0 if it is "abandoned". My second dependent variable is $M \& A$ pre-integration duration, calculated by the number of days between the announcement and the completion (as reported in Zephyr). Since Zephyr does not provide the completion dates for all transactions in my sample, a number of observations were removed due to missing data. Therefore, the sample for the model with $M \& A$ pre-integration duration as the dependent variable was reduced and had 132 observations in total. As this sample appears to be a non-random selected sample, concerns of sample selection bias may be raised. I will address this issue below, where I discuss my regression models.

Preliminary examinations with my data suggested that the variable $M \& A$ pre-integration duration was positively skewed to the right. Hence, I transformed it into natural logarithm to make its distribution look more normal [21].

\subsubsection{Independent variables}

My independent variable, revealed comparative advantage, was measured by Balassa index. As aforementioned, the Balassa indices used in this research were derived from Prof. Dr. Charles van Marrewijk. Since the

\footnotetext{
$\overline{3}$ These twelve manufacturing sectors include: Aircraft, Chemicals, Computers, Electronic equipment, Food products, Machinery, Measuring and control equip, Medical equipment, Petroleum and natural gas, Pharmaceutical products, Shipbuilding and railroad equip, and Steel works. These manufacturing sectors are considered to be among the most active in terms of M\&As during the chosen period [20].
}

industries in this Balassa index list are classified by Standard International Trade Classification (SITC) (revision 2) 2 digits, while firms' industries in the sample of data are classified by Standard Industrial Classification (SIC) (1987revision 2), I needed a concordance to link firms in my sample to the Balassa index. Following Brakman et al. (2010) [10], I firstly applied a concordance between SIC87 and the International Standard Industrial Classification - ISIC (revision $2)^{4}$. After that, a concordance between ISIC (revision 2) and SITC (revision 2) was applied ${ }^{5}$. The result of these steps was a concordance between SIC87 (revision 2) 2 digits and SITC (revision 2) 2 digits. Since the industries in Zephyr were classified by SIC 4-digit codes, I based on the description of SIC 4-digit codes and matched them with SITC 2-digit $\operatorname{codes}^{6}$ in the concordance. With this concordance table, I matched SITC 2-digit codes with both acquirers and targets in the sample of data. The next step was matching the Balassa index to partners involved in each deal, based on the countries that the firms are locating, SITC code and the announced year of the focal acquisition. Finally, I had two variables, Acquirer BI and Target BI, to measure revealed comparative advantage of the industries of acquirers and targets, respectively.

\subsubsection{Control variables}

In my model, I include a number of control variables, which relate to characteristics of both transactions and firms participating in M\&As. At the transaction-level, Cash payment is a binary variable, which is 1 if the payment method of the transaction is cash (as reported in Zephyr), and 0 otherwise. Deal size is the second control variable, which is measured by the natural logarithm of the deal value (provided by Zephyr).

\footnotetext{
${ }^{4}$ The concordance is available upon request

${ }^{5}$ For this concordance, please see: http://www.macalester.edu/research/economics/page/havema $\mathrm{n} /$ Trade.Resources/Concordances/FromISIC/3isic2sitc.txt

${ }^{6}$ I also used SITC 4-digit codes to have a more precise concordance. However, SITC 4-digit codes do not appear in the table because I only need SITC 2-digit for the Balassa indices. SITC 4-digit codes are only used for reference purpose.
} 
In addition to deal size, I also captured the relative size between the size of the focal deal and the size of the acquirer through a control variable named Deal size/Acquirer size, calculated by dividing deal values by acquirers' total assets.

At the firm-level, prior experience on acquisitions is suggested to significantly affect acquisition completion likelihood [4]. Hence I included in the model the variable Completion experience, which is measured by the total number of completed M\&A deals that the acquirer processed during three years prior to the announced year of the focal transaction. In addition, I accounted for the number of subsidiaries that targets possess, by including the variable Targets' subsidiaries, which reveals the size and complexity of targets.

\subsection{Estimation method}

I estimated two separate models: a binary logistic regression model with $M \& A$ completion likelihood and a linear regression model with $M \& A$ pre-integration duration as the dependent variables, respectively.

First, my logistic regression model can be expressed as:

$\mathrm{P}\left(\right.$ M\&A completion likelihood $\left.\mathrm{i}_{\mathrm{i}}\right)=1 /\left(1+\mathrm{e}_{\mathrm{i}}^{-\mathrm{z}}\right)$,

in which $\mathrm{Z}$ is a linear combination of the independent variables and coefficients which are going to be estimated:

$Z_{i}=\beta_{0}+\beta_{1}($ Cash payment $)+\beta_{2}\left(\right.$ ln_Deal size $\left._{i}\right)$ $+\beta_{3}\left(\right.$ Deal size/Acquirer size $\left.{ }_{\mathrm{i}}\right)+\beta_{4}\left(\bar{C}_{\text {Completion }}\right.$ experience $\left._{\mathrm{i}}\right)+\beta_{5}$ (Targets' subsidiaries $\left._{\mathrm{i}}\right)+$ $\beta_{6}\left(\right.$ Acquirer $\left.\mathrm{BI}_{\mathrm{i}}\right)+\beta_{7}\left(\right.$ Target $\left.\mathrm{BI}_{\mathrm{i}}\right)+\varepsilon_{\mathrm{i}}$.

Here, $\beta_{0}$ is the intercept, $\beta_{1,2, \mathrm{n}}$ are the regression coefficients, $\varepsilon_{\mathrm{i}}$ is the error term, and " $\mathrm{i}$ " refers to the $i^{\text {th }}$ deal of $260 \mathrm{M} \& \mathrm{~A}$ transactions taken into account.

Since some of the firms undertook more than one M\&A transaction over the observation period, my data make up an unbalanced panel. Thus, one option is to estimate my models with panel data techniques in order to account for within-firm correlation [2]. However, among 215 firms undertaking 260 transactions in the sample, there are only 11 firms that processed more than two transactions in the whole observation period, while there are 183 firms (85.1\% of the sample) undertaking only one transaction. Using panel data techniques may not be very meaningful in this case. Hence, I decided to treat the data as a pooled cross section.

Second, I estimated a multiple regression model with $M \& A$ pre-integration duration as the dependent variable. The regression analysis is performed following the below equation:

Ln_M\&A pre-integration duration ${ }_{i}=\beta_{0}+$ $\beta_{1}($ Cash payment $)+\beta_{2}($ ln_Deal size $)+\beta_{3}($ Deal size/Acquirer size $\left.{ }_{\mathrm{i}}\right)+\beta_{4}\left(\right.$ Completion experience $\left._{\mathrm{i}}\right)$ $+\beta_{5}\left(\right.$ Targets' subsidiaries $\left.{ }_{\mathrm{i}}\right)+\beta_{6}\left(\right.$ Acquirer $\left.\mathrm{BI}_{\mathrm{i}}\right)+$ $\beta_{7}\left(\right.$ Target $\left.\mathrm{BI}_{\mathrm{i}}\right)+\varepsilon_{\mathrm{i}}$

in which, $\beta_{0}$ is the unknown intercept, $\beta_{1,2, \mathrm{n}}$ are the regression coefficients, $\varepsilon_{\mathrm{i}}$ is the error term, and " $i$ " refers to the $i^{\text {th }}$ deal of 132 transactions taken into account.

As aforementioned, a challenge with the sample for this analysis is that, since I could not access data of abandoned dates in Zephyr, I could only observe duration for completed transactions. The dependent variable $M \& A$ pre-integration duration is, therefore, observed for a restricted, non-random sample, which may raise concerns of sample selection bias. To address this issue, I applied a Heckman style sample-selection procedure to find out whether there is correlation between unobservables affecting acquisition completion likelihood and acquisition duration. The result demonstrates that the null hypothesis of the presence of selection bias in the multiple regression model cannot be rejected. In other words, it suggests that selection bias may not generate any problematic impact on the results of the regression model.

Data in the sample for this regression model also make up an unbalanced panel. However, with the same reasons as for the logistic model (only two out of 116 firms processed more than two transactions), I chose to treat the data as a pooled non-section sample.

\section{Results}

The descriptive statistics of variables are presented in Table 1. The correlation matrix of all 
variables in the models is illustrated in Table 2. As can be seen from the correlation matrix, all of the correlation coefficients are well below $|0.7|$, which means that multicollinearity does not exist in my case. In addition, approximately $59 \%$ of the targets in my sample are active in an industry with a BI larger than 1 , i.e. having a revealed comparative advantage. This is also the percentage of acquirers' industries in the sample that exhibit a BI larger than 1.

Table 1. Descriptive statistics of variables

\begin{tabular}{lllll}
\hline Variable & Mean & S.d. & Min & Max \\
\hline \hline Acquisition Completion (dummy) & 0.915 & 0.280 & 0 & 1 \\
Acquisition Duration (natural log) & 4.163 & 1.092 & 0.693 & 7.227 \\
Cash Payment (dummy) & 0.566 & 0.497 & 0 & 1 \\
Deal Size (natural log) & 10.791 & 2.274 & 5.568 & 18.059 \\
Completion Experience & 2.853 & 4.895 & 0 & 29 \\
Targets' Subsidiaries & 0.981 & 4.308 & 0 & 53 \\
Deal Size/Acquirer Size & 0.590 & 1.459 & 0.0003 & 14.89 \\
Acquirer BI & 1.231 & 0.663 & 0.03 & 7.36 \\
Target BI & 1.377 & 1.330 & 0.02 & 16.71 \\
\hline
\end{tabular}

Table 2. Correlations for key study variables

\begin{tabular}{|c|c|c|c|c|c|c|c|c|}
\hline Variables & 1 & 2 & 3 & 4 & 5 & 6 & 7 & 8 \\
\hline $\begin{array}{l}\text { 1. Acquisition } \\
\text { completion } \\
\text { 2. Acquisition duration } \\
\text { (natural log) }\end{array}$ & & & & & & & & \\
\hline 3. Cash Payment & 0.01 & $-0.21 * *$ & & & & & & \\
\hline $\begin{array}{l}\text { 4. Deal Size (natural } \\
\log \text { ) }\end{array}$ & $-0.20 * *$ & $0.33 * *$ & $-0.17 * *$ & & & & & \\
\hline $\begin{array}{l}\text { 5. Deal Size/Acquirer } \\
\text { Size }\end{array}$ & -0.10 & -0.01 & -0.03 & $0.16^{*}$ & & & & \\
\hline $\begin{array}{l}\text { 6. Completion } \\
\text { Experience }\end{array}$ & 0.07 & 0.11 & 0.06 & $0.31 *$ & -0.07 & & & \\
\hline 7. Targets' Subsidiaries & $-0.20 * *$ & 0.13 & -0.05 & $0.17 * *$ & 0.00 & -0.04 & & \\
\hline 8. Acquirer BI & 0.00 & -0.10 & -0.06 & 0.04 & 0.09 & -0.07 & -0.05 & \\
\hline 9. Target BI & $-0.14 *$ & $0.25 * *$ & -0.09 & 0.09 & 0.01 & 0.08 & -0.07 & 0.08 \\
\hline
\end{tabular}

Table 3 illustrates the results from my analysis on the likelihood that an announced M\&A will be completed, which are used to test the "a" hypotheses. The results of the multiple regression analysis on the time-lapse between the announcement and completion of an acquisition are presented in Table 4. These results are used to test the "b" hypotheses. In both Tables, Model 1 provides results related to control variables only, while Model 2 shows results of all measures in the models. 
Table 3. M\&A completion likelihood results

\begin{tabular}{lcc}
\hline VARIABLES & \multicolumn{2}{c}{ M\&A Completion likelihood } \\
\cline { 2 - 3 } & Model 1 & Model 2 \\
& Controls only & Full model \\
\hline Cash payment & -0.290 & -0.454 \\
Deal Size (log value) & $(0.506)$ & $(0.525)$ \\
& $-0.259^{* *}$ & $-0.331^{* * *}$ \\
Deal Size/Acquirer Size & $(0.111)$ & $(0.107)$ \\
& -0.157 & -0.060 \\
Completion Experience & $(0.109)$ & $(0.060)$ \\
& 0.122 & $0.148^{* *}$ \\
Targets' Subsidiaries & $(0.080)$ & $(0.062)$ \\
& $-0.105 *$ & $-0.044 * *$ \\
Acquirer BI & $(0.055)$ & $(0.026)$ \\
& & -0.057 \\
Target BI & & $(0.333)$ \\
& & $-0.240^{* * *}$ \\
Intercept & & $(0.083)$ \\
& & $6.541 * * *$ \\
Cases in analysis & $5.509 * * *$ & $(1.441)$ \\
Log-likelihood & $(1.341)$ & 260 \\
Wald chi-square & 260 & -64.368 \\
Probability & -64.226 & 25.81 \\
Pseudo R & 21.94 & 0.0005 \\
\hline
\end{tabular}

Standard errors in parentheses. $* * * \mathrm{p}<0.01, * * \mathrm{p}<0.05, * \mathrm{p}<0.1$ Table 4. M\&A pre-integration duration results

\begin{tabular}{lcc}
\hline VARIABLES & \multicolumn{2}{c}{ M\&A pre-integration duration (log value) } \\
\cline { 2 - 3 } & Model 1 & Model 2 \\
& Controls only & Full model \\
\hline Cash Payment & $-0.345^{*}$ & -0.248 \\
& $(0.191)$ & $(0.183)$ \\
Deal Size (log value) & $0.163^{* * *}$ & $0.175^{* * *}$ \\
& $(0.051)$ & $(0.049)$ \\
Deal Size/Acquirer Size & -0.099 & -0.086 \\
& $(0.069)$ & $(0.067)$ \\
Completion Experience & 0.006 & -0.0004 \\
& $(0.014)$ & $(0.015)$ \\
Targets' Subsidiaries & 0.017 & 0.016 \\
& $(0.026)$ & $(0.023)$ \\
Acquirer BI & & $-0.180^{*}$ \\
Target BI & & $(0.100)$ \\
& & $0.338^{* *}$ \\
Intercept & & $(0.160)$ \\
& & $2.066^{* * *}$ \\
Cases in analysis & $2.448^{* * *}$ & $(0.627)$ \\
F-statistic & $(0.612)$ & 132 \\
Probability & 5.99 & 5.63 \\
R-squared & 0.0001 & 0.0000 \\
\hline
\end{tabular}

Robust standard errors in parentheses. $* * * \mathrm{p}<0.01, * * \mathrm{p}<0.05, * \mathrm{p}<0.1$ 
The null hypothesis that all parameters associated with explanatory variables are simultaneously equal to zero is rejected in all models at $1 \%$ level of significance. These are revealed through the values of the Wald chisquared test in the logistic regression models and the F-test in the multiple regression models.

First, results from the logistic regression model demonstrate a statistically insignificant relationship between Acquirer $B I$ and $M \& A$ completion likelihood. Contradictory to my prediction in Hypothesis 1a, that acquirers are active in industries with a revealed comparative advantage does not increase the likelihood of acquisition completion. However, there is an association between revealed comparative advantage of acquirers' industries and the timelapse of the pre-integration stage of M\&A deals. This is revealed through the significant and negative beta-value $(\mathrm{p}<0.1)$ of Acquirer $B I$ in the multiple regression model, as shown in Table 4. This finding is supportive to Hypothesis $1 \mathrm{~b}$ that the stronger acquirers are, the less time they may need to consummate an M\&A announcement.

Second, in terms of the relationship between Target BI and M\&A completion likelihood and $M \& A$ pre-integration duration, Model 2 of Table 3 shows a negative and significant coefficient $(\mathrm{p}<$ 0.01 ) of Target BI. As expected in Hypothesis 2a, the higher revealed comparative advantage that targets have, the more difficult it will be to acquire these firms. In addition, Target BI also has a positive and considerable beta-value ( $p$ $<0.05$ ) in Model 2 of Table 4. This result supports Hypothesis $2 \mathrm{~b}$ that acquisitions in which targets are active in industries with revealed comparative advantage will need more time to be completed than deals where targets' industries do not have this advantage.

Third, regarding control variables, the empirical analyses indicate that: (1) it is more difficult and takes more time to consummate acquisitions with large values than smaller acquisitions, (2) experience on completed acquisitions can support firms in completing a subsequent M\&A deal, (3) the likelihood of acquisition completion will possibly be reduced if targets possess many subsidiaries.

\section{Conclusion}

This paper focuses on a period of the M\&A process that recently has attracted increasing scholars' attention, which is the stage between the announcement and completion (or abandonment) of an acquisition. I attempt to provide more insightful answers to the question as to why a significant number of firms still walk away from announced takeovers, albeit the considerable losses caused by terminated acquisitions that they would have to bear. Although there have been more researchers drawing their attention to exploring determinants of M\&A outcomes in recent years, there is still a need for more investigation in this topic. This not only enriches the scarce literature on determinants of M\&A outcomes, but is also meaningful to firms that intend to undertake a merger or acquisition, because it can help firms avoid termination of acquisitions, and prolonged decision-making process, thus reducing financial losses and reputation damages.

I developed both theories and empirical analyses to investigate the effects of revealed comparative advantage on the likelihood to complete acquisitions as well as the duration it takes to consummate acquisitions. With a sample of 260 mergers and acquisitions, occurring in 12 manufacturing industries in 21 OECD countries from 1995 to 2000, I found empirical evidence for my proposals on the effects of revealed comparative advantage on acquisition completion likelihood as well as acquisition duration. My findings suggest that in a transaction where the prospective target comes from an industry that has a comparative advantage, the acquirer will have to face with higher competition caused by other rivals that also want to acquire such an attractive target. The larger comparative advantage the target owns, the more firms may want to bid for it, thus the more difficult to consummate the takeover. Furthermore, transactions involving 
these targets may also take more time to be completed than the others.

From the side of acquirers, since strong firms are more motivated to engage in M\&A activities, they may have more opportunities to gain experience and skills related to managing the M\&A process. These experience and skills, though not helping firms to increase the probability of successfully acquiring a target, can reduce the length of the decision-making stage of the takeover process. A possible reason is that with the skills and experience obtained from previous bids, acquirers may know how to effectively communicate and negotiate with not only targets, but also shareholders and the press in subsequent acquisitions. They may also know how to deal with competition authorities, as well as how to handle intermediary services such as accounting and banking services in the most effective way. Hence, they can shorten the time-lapse of the pre-consummation period, which may help save time and money for both acquirers and targets.

Apart from the above findings, my research still exhibits several limitations, which may also be considered as fruitful suggestions for research in the future. First of all, due to limitations in accessing to secondary data on M\&As, the empirical analyses only focused on manufacturing sectors in a short period of five years. Research may benefit by testing my hypotheses in other sectors such as services and in a longer time range. Furthermore, I could only observe the duration of the decision-making process of completed transactions. Including abandoned acquisitions in research on the duration of the intermediary phase of M\&As may provide more precise findings on this topic. Finally, as suggested from empirical results, the effects of control variables which relate to firms' characteristics and transaction characteristics on the dependent variables are different. Therefore, beside exploring effects of isolated determinants, it may be fascinating to study the impacts of determinants in group level, such as transactionlevel and firm-level.

\section{References}

[1] Chakrabarti, A. and Mitchell, W., The role of geographic distance in completing related acquisitions: Evidence from U.S. chemical manufacturers, Strategic Management Journal, doi: 10.1002/smj.2366 (2015).

[2] Dikova, D., Rao Sahib, P. and Witteloostuijn, A. v., Cross-border acquisition abandonment and completion: The effect of institutional differences and organizational learning in the international business service industry, 19812001, Journal of International Business Studies, 41 (2010) 223.

[3] Angwin, D. N., Paroutis, S. and Connell, R., Why good things don't happen: the micro foundations of routines in the M\&A process, Journal of Business Research, 68 (2015) 1367.

[4] Muehlfeld, K., Rao Sahib, P. and van Witteloostuijn, A., A contextual theory of organizational learning from failures and successes: A study of acquisition completion in the global newspaper industry, 1981-2008, Strategic Management Journal, 33 (2012) 938.

[5] Sudarsanam, P. S., The role of defensive strategies and ownership structure of target firms: Evidence from UK hostile takeover bids, European Financial Management, 1 (1995) 223.

[6] Balassa, B., Trade liberalization and 'revealed' comparative advantage, The Manchester School of Economic and Social Studies, 33 (1965) 92.

[7] Cooper, J., Can Russia compete in the global economy?, Eurasian Geography and Economics, 47-4 (2007) 407.

[8] Ferto, I. and Hubbard, L. J., Revealed comparative advantage and competitiveness in Hungarian Agri-Food Sectors, The World Economy, 26-2 (2003) 247.

[9] Havrila, I. and Gunawardana, P., 2003, Analysing comparative advantage and competitiveness: an application to Australia's textile and clothing industries, Australian Economic Papers, 42-1 (2003) 103.

[10] Brakman, Garretsen, S.H., Marrewijk, C.v., and Witteloostuijn, Cross-border mergers and acquisitions: on revealed comparative advantage and merger waves, 2010 mimeo., University of Groningen.

[11] Neary, J.P., Cross-border mergers as instruments of comparative advantage, Review of Economic Studies, 74 (2007) 1229. 
[12] Bainbridge, S. M., Exclusive merger agreements and lockups in negotiated corporate acquisitions, Minnesota Law Review, 75-1 (1990) 239.

[13] Lyons, B., Endogenous merger proposals and Institutional design for merger regulation, Working paper 2006, ESRC Centre for Competition Policy, University of East Anglia, Norwich. NR4 7TJ, United Kingdom.

[14] Luo, Y., Do insiders learn from outsiders? Evidence from mergers and acquisitions, Journal of Finance, 60-4 (2005) 1951.

[15] Haspeslagh, P. C. and Jemison, D. B., Managing acquisitions, New York, NY: Free Press, 1991.

[16] Liesner, H. H., The European common market and British industry, Economic Journal, 68 (1958) 302.
[17] Pickering, J. F., The causes and consequences of abandoned mergers, Journal of Industrial Economics, 31-3 (1983) 276.

[18] Aguilera, R. V., Dencker, J. C., Determinants of acquisition completion: a relational perspective, Working Paper (2008), University of Illinois at Urbana-Champaign.

[19] Graebner M. E., and Eisenhardt, K. M., The seller's side of the story: acquisition as courtship and governance as syndicate in entrepreneurial firms, Administrative Science Quarterly, 49 (2004) 366.

[20] Harford, J., What drives merger waves?, Journal of Financial Economics, 77 (2005) 529.

[21] Carter, H. R., Griffiths, W. E. and Lim, G. C., Principles of Econometrics, 3rd edition, Wiley, US, 2008. 